\title{
Parathyroid Hormone Levels in the Prediction of Ischemic Stroke Risk
}

\author{
Güner Çelik, ${ }^{1}$ Ali Doğan, ${ }^{2}$ Şefik Dener, ${ }^{3}$ Şerefnur Öztürk, ${ }^{4}$ \\ Sevsen Kulaksızoğlu, ${ }^{5}$ and Hakan Ekmekçi ${ }^{4}$ \\ ${ }^{1}$ Beyhekim State Hospital, Department of Neurology, Konya, Turkey \\ ${ }^{2}$ Bandirma State Hospital, Department of Neurology, Balıkesir, Turkey \\ ${ }^{3}$ Department of Neurology, Başkent University, Konya Training and Research Hospital, Konya, Turkey \\ ${ }^{4}$ Department of Neurology, Selçuk Medical Faculty, Selçuk University, Konya, Turkey \\ ${ }^{5}$ Department of Biochemistry, Başkent University, Konya Training and Research Hospital, Konya, Turkey
}

Correspondence should be addressed to Güner Çelik; gunerkoyuncu@mynet.com

Received 13 October 2016; Accepted 23 November 2016; Published 2 January 2017

Academic Editor: Kailash Gulshan

Copyright ( 2017 Güner Çelik et al. This is an open access article distributed under the Creative Commons Attribution License, which permits unrestricted use, distribution, and reproduction in any medium, provided the original work is properly cited.

Objective. It was examined whether PTH and 25-dihydroxyvitamin D $(25(\mathrm{OH}) \mathrm{D})$ levels, together or separately, are indicators of the risk of stroke. Materials and Methods. This prospective study was performed at two centers. In the study, 100 patients diagnosed with acute ischemic stroke and 100 control individuals in the same age range were examined. In addition to neurological examination, cranial imaging, extensive routine blood chemistry, PTH, and 25(OH)D levels were evaluated in all cases. Stroke risk factors were determined. Logistic regression was used for statistical analysis. Results. A total of 60 patients and 79 control individuals were included in the study. Different estimation models were designed in order to examine the relationship between PTH and 25(OH)D levels with stroke. According to modeling results, it was determined that the most effective predictor for risk of stroke was 25(OH)D levels, followed by hypertension and PTH levels, respectively. Conclusion. PTH and 25(OH)D levels together can make important contributions to determination of stroke risk, and further investigations are needed to understand this relationship more fully.

\section{Introduction}

The key role of parathyroid hormone (PTH) in bone health and homeostasis is well known. However, recent studies have indicated that PTH has various effects on other organs and tissues like $25(\mathrm{OH}) \mathrm{D}$. PTH shows the effect of PTH receptors in tissues through which receptors are expressed in smooth muscle cells on the vascular wall, endothelium, and myocardium [1]. Its level is frequently increased by 25(OH)D (25-dihydroxyvitamin D) deficiency or, to a lesser extent, chronic renal failure. However, some studies have demonstrated that elevated PTH levels are common even in healthy people with neither $25(\mathrm{OH}) \mathrm{D}$ deficiency nor chronic renal failure [2]. Elevated PTH levels raise blood pressure and cardiac contractility, resulting in fibrosis, apoptosis, and hypertrophy in cardiomyocytes of the left ventricle and vascular smooth muscle cells [3]. Several recent studies have demonstrated that it is associated with various cardiovascular conditions such as endothelial dysfunction, vascular stiffness, and calcification [4], increased aortic pulse pressure [5], reduced great artery elasticity [6], coronary microvascular dysfunction, and hypertension [7]. Furthermore, it has also been shown that increased PTH levels may affect the cardiovascular system by stimulating cytokine release from lymphocytes and vascular smooth muscle cells $[1,8]$. It has been argued that PTH confers a risk for cardiovascular disease even at normal or slightly elevated levels and in the absence of mineral metabolism disorders. Since all these data suggest that increased PTH levels may increase risk for cerebrovascular disease, the aim of this study was to investigate the correlation between PTH levels and stroke and to study $25(\mathrm{OH}) \mathrm{D}$ because of its close correlation with PTH. 
TABLE 1: Age distribution in the patient and control groups.

\begin{tabular}{lllcccrr}
\hline & Group & $n$ & Mean & Std. deviation & Std. error mean & Test & $p$ \\
\hline \multirow{2}{*}{ Age } & Patient & 60 & 61.2833 & 6.55897 & .84676 & $t$ & \multirow{2}{*}{0.449} \\
& Control & 79 & 62.2152 & 7.59668 & .85469 & -0.759 & \\
\hline
\end{tabular}

\section{Materials and Methods}

This prospective study was conducted in two separate centers between 2010 and 2014. The study group included 100 patients admitted to emergency department or outpatient clinics for symptoms of acute stroke and were diagnosed with acute ischemic stroke using cranial imaging methods. The control group consisted of 100 age-matched subjects with completely normal MRI cranial examination results, no history of stroke or transient ischemic attack, and no signs or symptoms of cerebrovascular disease. In both groups, subjects using supplemental calcium or vitamin D were excluded, as well as those with chronic renal failure, chronic liver disease, or osteoporosis.

In addition to obtaining a detailed medical history and performing a thorough neurological examination, either cranial magnetic resonance imaging (MRI) or computerized tomography (CT) was obtained for differential diagnosis at admission in all subjects. Age, gender, arterial blood pressure, and electrocardiography were recorded for all subjects in both groups. Additionally, comprehensive blood biochemistry and levels of 25(OH)D and PTH were measured in all subjects. Risk factors for stroke (hypertension (HT), diabetes mellitus $(\mathrm{DM})$, atrial fibrillation $(\mathrm{AF})$, coronary artery disease (CAD), history of myocardial infarction (MI), tobacco or alcohol use, and obesity) were recorded. Blood samples were obtained by venipuncture after an overnight fast and placed into tubes that were protected from sunlight. Sera were separated and stored at $-80^{\circ} \mathrm{C}$ within $30 \mathrm{~min}$ of collection. Serum PTH levels were determined by a chemiluminescent microparticle immunoassay (CMIA) method in an Abbott Architect i2000 analyzer using the Abbott Architect Intact PTH assay kit; the reference range was set at $10-65 \mathrm{pg} / \mathrm{mL}$. The same method was also used to determine $25(\mathrm{OH}) \mathrm{D}$ levels. The reference range for $25(\mathrm{OH}) \mathrm{D}$ was set at $10-55 \mu \mathrm{g} / \mathrm{L}$.

This research project was approved by the local ethics committee.

2.1. Statistical Analysis. Since the data regarding ages and PTH levels was normally distributed, a two-sample independent $t$-test was used to compare the two groups (patient and control groups). 25(OH)D levels were not normally distributed, and thus the nonparametric Mann-Whitney $U$ test was used in order to compare the two groups. Gender distribution between the two groups was evaluated using the chisquare test. Logistic regression analysis was used in order to properly estimate the stroke patients and healthy individuals $(n=139)$. Three appropriate logistic regression models were designed using efficient and significant predictors. In the first model, 25(OH)D and PTH levels were used for estimation of stroke risk. In the second model cardiac risk factors (AF,
$\mathrm{CAD}$, and $\mathrm{MI}$ ) were used in addition to $25(\mathrm{OH}) \mathrm{D}$ and $\mathrm{PTH}$ levels for stroke risk estimation. In the third model, 25(OH)D and PTH levels as well as all cardiovascular risk factors were evaluated. For these models, the formula of hazard ratio (HR) was used. For example, HR for Model 1.3 is

$$
\pi\left(\mathrm{OH}_{25} ; \mathrm{PTH}\right)=1-\frac{e^{-0.757+0.113\left(\mathrm{OH}_{25}\right)-0.013(\mathrm{PTH})}}{1+e^{-0.757+0.113\left(\mathrm{OH}_{25}\right)-0.013(\mathrm{PTH})}} .
$$

If 25(OH)D and PTH levels are 11.9 and 164.7 in the patient, respectively, ischemic stroke risk is estimated as $83.4 \%$.

$$
\begin{aligned}
\pi(11.90 ; 164.7) & =1-\frac{e^{-0.757+0.113(11.9)-0.013(164.7)}}{1+e^{-0.757+0.113(11.9)-0.013(164.7)}} \\
& =1-0.1659=83.4 \% .
\end{aligned}
$$

If 25(OH)D and PTH levels are 19.20 and 60.3 in the patient, respectively, ischemic stroke risk is estimated as $35.3 \%$.

$$
\begin{aligned}
\pi(19.20 ; 60.30) & =1-\frac{e^{-0.757+0.113(19.20)-0.013(60.30)}}{1+e^{-0.757+0.113(19.20)-0.013(60.30)}} \\
& =1-0.6463=35.3 \% .
\end{aligned}
$$

The study power for $25(\mathrm{OH}) \mathrm{D}$ measurements was $92 \%$, using a standard deviation of 8.05 and difference value of 5 , with 60 patients in each group. For PTH measurements, the study power was $79 \%$ using a standard deviation of 38.91 , difference value of 20, and 59 patients in each group. Minitab Release 14.0 and SPSS 15.0 for Windows (SPSS, Inc., Chicago, IL) statistical programs were used for statistical analyses.

\section{Results}

This study included a total of 200 subjects: 100 patients with acute stroke and 100 control subjects. Subjects with problematic blood sampling, storage, or analysis for PTH and $25(\mathrm{OH}) \mathrm{D}$ levels were excluded from the study. Subjects with extreme measurement values who created heterogeneity in the distribution of both groups and those who were difficult to age-match between the groups (the extremely old or young) were excluded. Obese subjects and those with habits of tobacco or alcohol use were also excluded due to the small number and unequal distribution of these individuals across the groups. After the completion of the above exclusion procedures, data from a total of 60 patients and 79 control subjects remained in the data set used for $25(\mathrm{OH}) \mathrm{D}$ analysis. PTH analysis was performed after excluding 1 more subject with PTH levels of approximately $500 \mathrm{pg} / \mathrm{mL}$.

No significant difference was found between the mean age and gender distribution of both groups (Tables 1 and 2). 
TABLE 2: Gender distribution in the patient and control groups.

\begin{tabular}{lcccc}
\hline & & \multicolumn{2}{c}{ Gender } & \multirow{2}{*}{ Total } \\
& & Female & Male & \\
\hline \multirow{2}{*}{ Patient } & Count & 25 & 35 & 60 \\
& \% within group & $41.7 \%$ & $58.3 \%$ & $100.0 \%$ \\
\multirow{2}{*}{ Control } & Count & 32 & 47 & 79 \\
& \% within group & $40.5 \%$ & $59.5 \%$ & $100.0 \%$ \\
\hline \multirow{2}{*}{ Total } & Count & 57 & 82 & 139 \\
& \% within group & $41.0 \%$ & $59.0 \%$ & $100.0 \%$ \\
\hline
\end{tabular}

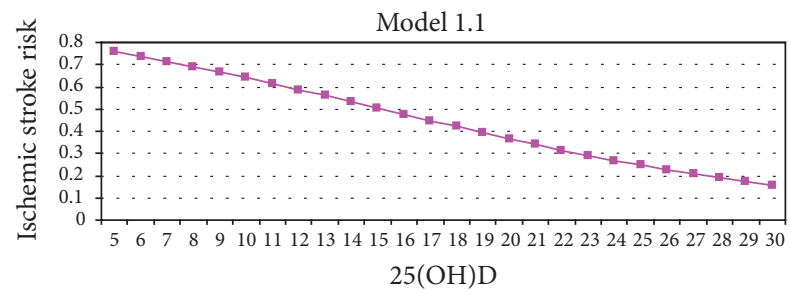

FIGURE 1

As shown in Table 3, the mean $25(\mathrm{OH}) \mathrm{D}$ level was significantly lower in the patient group $(15.7 \pm 4.27)$ compared to the control group $(20.1 \pm 8.05)(Z=3.147, p=0.002)$. In contrast to the vitamin D level, the PTH level was significantly higher in the patient group $(82.83 \pm 38.91)$ compared to the control group $(64.74 \pm 28.80)(t=-2.998, p=0.002)$. These two comparisons were strongly significant.

Different prediction models were used to examine the association between stroke and PTH, 25(0H)D levels. First, it was determined whether PTH and $25(\mathrm{OH}) \mathrm{D}$ could be used as markers for predicting stroke risk (Table 4). The abilities of $25(\mathrm{OH}) \mathrm{D}$ and PTH levels, both alone and in conjunction, to accurately predict stroke patients and healthy subjects were tested, as outlined by Model 1. According to this model, $25(\mathrm{OH}) \mathrm{D}$ levels had an accurate prediction rate of $48.3 \%$ for stroke patients and $70.9 \%$ for healthy subjects; it has an overall accurate prediction rate of $61.2 \%$ (wald = $12.215, p=0.000$ ). When the PTH level was used as the prediction marker, the accurate prediction rate was $35.6 \%$ for stroke patients, $81.8 \%$ for the controls, and $61.8 \%$ as an overall accurate prediction rate (wald $=8.129, p=0.004$ ). Models 1.1 and 1.2 are presented in Figures 1 and 2 graphically. When PTH and 25(OH)D were analyzed together (Model 1.3 ), the accurate prediction rate increased to $57.6 \%$ and the overall accurate prediction rate increased to $64 \%$. The $20 \%$ increase in accurate prediction rate indicated that both factors were more effective for accurate prediction when used in conjunction (wald $=4.822, p=0.028$ ). Ten percent of 30 patients incorrectly diagnosed by $25(\mathrm{OH}) \mathrm{D}$ were accurately categorized by PTH (Model 1.4) in a statistically significant manner (wald $=3.911, p=0.048$ ).

$25(\mathrm{OH}) \mathrm{D}$ and $\mathrm{PTH}$, both alone and in conjunction, were also used as prediction tools in the presence of cardiac risk factors in Model 2 (Table 5). In this model, 25(OH)D was used

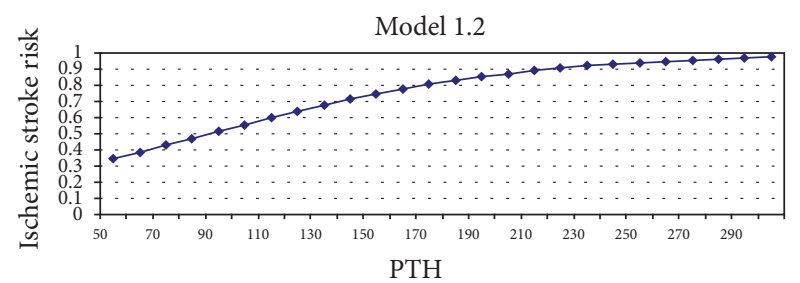

Figure 2

in conjunction with risk factors such as $\mathrm{CAD}, \mathrm{MI}$, and $\mathrm{AF}$ (Model 2.1). The accurate prediction rate of the model was 53.3\% $(p=0.001)$ for the stroke patients and 76.9\% ( $p=$ NS) for the healthy subjects. When used in conjunction with cardiac risk factors, the accurate prediction rate of PTH was $45.8 \%(p=0.41)$ (Model 2.2). This result was also statistically significant, although it was weaker than that of $25(\mathrm{OH}) \mathrm{D}$. The accurate prediction rate for the healthy subjects was $90.8 \%(p=\mathrm{NS})$. When both $25(\mathrm{OH}) \mathrm{D}$ and PTH were used in conjunction with other cardiac risk factors (Model 2.3), the accurate prediction rate was the same as that obtained without taking cardiac risk factors into account $(57.6 \%)(p=$ $0.99)$. Among all risk factors considered, CAD significantly contributed to accurate prediction. However, this effect was significantly weaker than those of $25(\mathrm{OH}) \mathrm{D}$ and PTH. Of 28 patients not accurately predicted by an analysis using cardiac risk factors and $25(\mathrm{OH}) \mathrm{D}$ together, only $7.1 \%$ were accurately predicted by PTH and IHD, and this difference did not reach statistical significance.

Model 3 used 25(OH)D and PTH in conjunction with other cardiovascular risk factors (HT, DM, and lipid levels) in addition to the cardiac risk factors studied in Model 2. Table 6 shows the effect and statistical significance of the predictors used in this analysis. The model in which $25(\mathrm{OH}) \mathrm{D}$ was used with all of these risk factors (Model 3.1) had an accurate prediction rate of $68.3 \%$ for the stroke patients. Compared to all other factors, $25(\mathrm{OH}) \mathrm{D}$ had the greatest effect on the accurate prediction rate $(p=0.002)$. The effect of HT was smaller, but statistically more significant than that of $25(\mathrm{OH}) \mathrm{D}(p=0.010)$. Other risk factors had no effect on the accurate prediction rate. When PTH was used with all cardiovascular risk factors (Model 3.2) the accurate prediction rate was 59.3\%. In this analysis, the effect of PTH on the result was statistically significant ( $p=0.019)$, but less than that of HT. The most powerful effect in the analysis was that of HT $(p=0.002)$. Other risk factors had no effect on the result. When both $25(\mathrm{OH}) \mathrm{D}$ and PTH were used together with all other risk factors (Model 3.3), the accurate prediction rate was found to be $69.5 \%$. In this analysis it was observed that both $25(\mathrm{OH}) \mathrm{D}$ and HT were two important indicators for predicting strokes, with the effect of $25(\mathrm{OH}) \mathrm{D}$ being more powerful than that of HT. Furthermore, effect of PTH was minimal and not statistically significant in this analysis. Model 3.4, in which PTH and other risk factors were used, was not successful for nineteen patients who were incorrectly diagnosed using $25(\mathrm{OH}) \mathrm{D}$ levels. In conclusion, a combined review of all analyses revealed that $25(\mathrm{OH}) \mathrm{D}$ was 
TABLE 3: Comparison of 25(OH)D and PTH levels between the patients and controls.

\begin{tabular}{|c|c|c|c|c|c|c|}
\hline & Group & $N$ & Mean & Std. deviation & Test & Sig \\
\hline \multirow{2}{*}{$25(\mathrm{OH}) \mathrm{D}$} & Patient & 60 & 15.7117 & 4.27599 & \multirow{2}{*}{$Z=-3.147$} & \multirow{2}{*}{0.002} \\
\hline & Control & 79 & 20.1608 & 8.05743 & & \\
\hline \multirow{2}{*}{ PTH } & Patient & 59 & 82.8373 & 38.91614 & \multirow{2}{*}{$t=-2.998$} & \multirow{2}{*}{0.002} \\
\hline & Control & 77 & 64.7416 & 28.80296 & & \\
\hline
\end{tabular}

TABLE 4: Rates of accurate prediction of patients and disease-free subjects by 25(OH)D and PTH level (Model 1).

\begin{tabular}{|c|c|c|c|c|c|c|c|c|c|}
\hline & $B$ & SE & Wald & $\mathrm{df}$ & Sig. & $\exp (B)$ & $\begin{array}{l}\text { Accurate } \\
\text { prediction rate } \\
\text { of the patient } \\
\text { group }\end{array}$ & $\begin{array}{l}\text { Accurate } \\
\text { prediction rate } \\
\text { of the control } \\
\text { group }\end{array}$ & $\begin{array}{l}\text { Overall accurate } \\
\text { prediction rate }\end{array}$ \\
\hline \multicolumn{10}{|l|}{ Model 1.1} \\
\hline $25(\mathrm{OH}) \mathrm{D}$ & .113 & .032 & 12.215 & 1 & .000 & 1.119 & \multirow{2}{*}{48.3} & \multirow{2}{*}{70.9} & \multirow{2}{*}{61.2} \\
\hline Constant & -1.713 & .577 & 8.814 & 1 & .003 & .180 & & & \\
\hline \multicolumn{10}{|l|}{ Model 1.2} \\
\hline PTH & -.017 & .006 & 8.129 & 1 & .004 & .983 & \multirow{2}{*}{35.6} & \multirow{2}{*}{81.8} & \multirow{2}{*}{61.8} \\
\hline Constant & 1.477 & .457 & 10.429 & 1 & .001 & 4.379 & & & \\
\hline \multicolumn{10}{|l|}{ Model 1.3} \\
\hline $25(\mathrm{OH}) \mathrm{D}$ & .113 & .034 & 10.903 & 1 & .001 & 1.119 & \multirow{3}{*}{57.6} & \multirow{3}{*}{68.8} & \multirow{3}{*}{64.0} \\
\hline PTH & -.013 & .006 & 4.822 & 1 & .028 & .987 & & & \\
\hline Constant & -.757 & .790 & .918 & 1 & .338 & .469 & & & \\
\hline \multicolumn{10}{|c|}{$\begin{array}{l}\text { Model } 1.4 \text { (the } \\
\text { classification of } 30 \\
\text { patients unclassified by } \\
\text { Model 1.1) }\end{array}$} \\
\hline PTH & -.012 & .006 & 3.911 & 1 & .048 & .988 & \multirow{2}{*}{10.0} & \multirow{2}{*}{98.7} & \multirow{2}{*}{73.8} \\
\hline Constant & 1.810 & .499 & 13.149 & 1 & .000 & 6.111 & & & \\
\hline
\end{tabular}

the most important factor for stroke prediction, followed by HT and PTH, in descending order. The effect of CAD was minimal and not statistically significant.

\section{Discussion}

In examining the association between serum PTH levels and cerebrovascular disease, as well as the contribution of $25(\mathrm{OH}) \mathrm{D}$, this study made some important conclusions. First, serum PTH levels were significantly higher and $25(\mathrm{OH}) \mathrm{D}$ levels were significantly lower in the patient group compared to the control group. Numerous studies have stressed the association between serum 25(OH)D levels, cardiovascular disorders $[9,10]$, and mortality [11]. It has also been shown that $25(\mathrm{OH}) \mathrm{D}$ levels are lower in patients with stroke $[12,13]$. Moreover, $25(\mathrm{OH}) \mathrm{D}$ deficiency increases risk of stroke and even affects stroke prognosis [14], causing more stroke-related fatal outcomes [15]. In contrast, the number of studies examining the association between increased PTH levels and cardiovascular diseases $[6,16]$, mortality [11, 17], and particularly, stroke $[18,19]$ is quite limited. Of these studies, one conducted by Sato et al. detected a decrease in serum 25(OH)D levels and BMD values and an increase in serum ionized calcium and PTH levels in female subjects with ischemic stroke. In the patient group the incidences of hypertension and coronary artery disease were higher than in the control group, as was the prevalence of lacunar infarcts; that group also entered menopause earlier [20]. A study examined the association between stroke and $\mathrm{PTH}$ in patients with hypercalcemia, and elevated PTH levels were associated with stroke, the incidence of which was $7.1 \%$ in patients with primary hyperparathyroidism [19].

The second finding of our study was that both $\mathrm{PTH}$ and $25(\mathrm{OH}) \mathrm{D}$ levels were two important markers that could be used to predict the future risk of stroke. Of these two predictors, $25(\mathrm{OH}) \mathrm{D}$ was a fairly powerful marker, while PTH was weaker, although still statistically. When both predictors were used together, the accurate prediction rate for stroke was further increased. This demonstrated that PTH is an important marker for defining stroke risk, but its predictive power is enhanced when used in conjunction with $25(\mathrm{OH}) \mathrm{D}$. This suggests that combined use of these two markers would be a more powerful marker in risk assessment.

There exist some studies relating low 25(OH)D levels to increased risk for all cardiovascular disorders, including 
TABLE 5: Rates of accurate prediction of patients and disease-free subjects by 25(OH)D and PTH used in conjunction with cardiac risk factors (Model 2).

\begin{tabular}{|c|c|c|c|c|c|c|c|c|c|}
\hline & $B$ & SE & Wald & $\mathrm{df}$ & Sig. & $\exp (B)$ & $\begin{array}{l}\text { Accurate } \\
\text { prediction rate } \\
\text { of the patient } \\
\text { group }\end{array}$ & $\begin{array}{l}\text { Accurate } \\
\text { prediction rate } \\
\text { of the control } \\
\text { group }\end{array}$ & $\begin{array}{l}\text { Overall accurate } \\
\text { prediction rate }\end{array}$ \\
\hline \multicolumn{10}{|l|}{ Model 2.1} \\
\hline $25(\mathrm{OH}) \mathrm{D}$ & .130 & .039 & 11.214 & 1 & .001 & 1.139 & \multirow{5}{*}{53.3} & \multirow{5}{*}{76.9} & \multirow{5}{*}{66.7} \\
\hline $\mathrm{CAD}(1)$ & 1.169 & .567 & 4.245 & 1 & .039 & 3.217 & & & \\
\hline $\mathrm{MI}(1)$ & 21.211 & 12641.233 & .000 & 1 & .999 & 1628236695.777 & & & \\
\hline $\mathrm{AF}(1)$ & 21.822 & 12669.616 & .000 & 1 & .999 & 3001279038.402 & & & \\
\hline Constant & -45.710 & 17897.485 & .000 & 1 & .998 & .000 & & & \\
\hline \multicolumn{10}{|l|}{ Model 2.2} \\
\hline PTH & -.013 & .006 & 4.162 & 1 & .041 & .987 & \multirow{5}{*}{45.8} & \multirow{5}{*}{90.8} & \multirow{5}{*}{71.1} \\
\hline $\operatorname{IHD}(1)$ & 1.319 & .561 & 5.527 & 1 & .019 & 3.738 & & & \\
\hline $\mathrm{MI}(1)$ & 20.396 & 13141.236 & .000 & 1 & .999 & 721159600.690 & & & \\
\hline $\mathrm{AF}(1)$ & 21.526 & 13937.969 & .000 & 1 & .999 & 2232101328.556 & & & \\
\hline Constant & -41.590 & 19156.176 & .000 & 1 & .998 & .000 & & & \\
\hline \multicolumn{10}{|l|}{ Model 2.3} \\
\hline $25(\mathrm{OH}) \mathrm{D}$ & .132 & .041 & 10.554 & 1 & .001 & 1.141 & \multirow{6}{*}{57.6} & \multirow{6}{*}{81.6} & \multirow{6}{*}{71.1} \\
\hline PTH & -.009 & .007 & 1.773 & 1 & .183 & .991 & & & \\
\hline $\mathrm{CAD}(1)$ & 1.134 & .582 & 3.795 & 1 & .051 & 3.108 & & & \\
\hline $\mathrm{MI}(1)$ & 20.780 & 12788.170 & .000 & 1 & .999 & 1058694576.339 & & & \\
\hline $\mathrm{AF}(1)$ & 21.873 & 13324.999 & .000 & 1 & .999 & 3156046476.935 & & & \\
\hline Constant & -44.722 & 18468.707 & .000 & 1 & .998 & .000 & & & \\
\hline \multicolumn{10}{|c|}{$\begin{array}{l}\text { Model } 2.4 \text { (the } \\
\text { classification of } 28 \\
\text { patients unclassified by } \\
\text { Model } 2.1 \text { ) }\end{array}$} \\
\hline PTH & -.012 & .007 & 2.694 & 1 & .101 & .988 & \multirow{3}{*}{7.1} & \multirow{3}{*}{98.7} & \multirow{3}{*}{74.3} \\
\hline $\operatorname{IHD}(1)$ & .361 & .741 & .237 & 1 & .626 & 1.435 & & & \\
\hline Constant & 1.513 & .804 & 3.538 & 1 & .060 & 4.540 & & & \\
\hline
\end{tabular}

stroke [10, 21, 22], MI, and carotid atherosclerosis [14, 23]. However, studies have predominantly reported that increased PTH caused vascular abnormalities rather than stroke and mentioned it as a risk factor for cardiovascular disorders.

In two Swedish population studies of more than 1000 patients over 70 years of age, Hagström et al. reported that PTH was a powerful predictor for both clinical and subclinical atherosclerosis. In this study, plasma PTH levels above $50 \mathrm{pg} / \mathrm{mL}$ conferred a $20 \%$ risk for cardiovascular mortality [24]. In addition, several studies have supported the notion that increased PTH levels cause atherosclerosis or vessel wall dysfunction $[16,25,26]$.

Anderson et al. found that PTH levels were higher in subjects with increased prevalence of cardiovascular risk factors (HT, DM). They also observed that PTH levels were elevated before other risk factors were apparent, which suggests that PTH may contribute to the development of such risk factors [2]. Another study found that increased serum PTH levels were correlated to the number of stenotic arteries, $\mathrm{HT}$, and low ejection fraction.
In a population-based study by Wannamethee et al. examining the association between heart failure (HF) and PTH, increased PTH levels were correlated with HF risk, although such a risk was not related to mineral metabolism and $25(\mathrm{OH}) \mathrm{D}$. This was explained by the hypothesis that, in the absence of chronic renal failure, PTH exerts its cardiac actions via PTH receptors found in myocardium [1]. In a study by Bansal et al. increased serum PTH levels were correlated with increased risk of $\mathrm{HF}$ and left ventricular mass, although such an association was absent for 25(OH)D [27].

Multiple studies have shown that PTH was predictive for vascular disease and death associated with disorders of mineral metabolism including primary and secondary hyperparathyroidism and CRF $[18,28,29]$. Hagström et al. explained the association between PTH and atherogenesis in the following way: vascular calcification and remodeling result from direct PTH receptor interaction on the vessel wall, indirect inflammation, and vascular dysfunction. In addition, increased PTH levels are associated with inflammation markers, which are now considered cardiovascular risk 
TABLE 6: Rates of accurate prediction of patients and disease-free subjects by 25(OH)D and PTH used in conjunction with all cardiac risk factors (Model 3).

\begin{tabular}{|c|c|c|c|c|c|c|c|c|c|}
\hline & $B$ & $\mathrm{SE}$ & Wald & $\mathrm{df}$ & Sig. & $\exp (B)$ & $\begin{array}{l}\text { Accurate } \\
\text { prediction rate } \\
\text { of the patient } \\
\text { group }\end{array}$ & $\begin{array}{l}\text { Accurate } \\
\text { prediction rate } \\
\text { of the control } \\
\text { group }\end{array}$ & $\begin{array}{l}\text { Overall accurate } \\
\text { prediction rate }\end{array}$ \\
\hline \multicolumn{10}{|l|}{ Model 3.1} \\
\hline D_VIT_OH_25 & .129 & .042 & 9.325 & 1 & .002 & 1.137 & \multirow{10}{*}{68.3} & \multirow{10}{*}{80.8} & \multirow{10}{*}{75.4} \\
\hline $\mathrm{CAD}(1)$ & .472 & .642 & .539 & 1 & .463 & 1.603 & & & \\
\hline MI(1) & 21.250 & 12597.619 & .000 & 1 & .999 & 1692925884.235 & & & \\
\hline $\mathrm{AF}(1)$ & 21.894 & 12648.666 & .000 & 1 & .999 & 3224649359.264 & & & \\
\hline $\mathrm{HT}(1)$ & 1.251 & .484 & 6.691 & 1 & .010 & 3.495 & & & \\
\hline $\mathrm{DM}(1)$ & -.255 & .530 & .232 & 1 & .630 & .775 & & & \\
\hline TRG & -.005 & .004 & 2.421 & 1 & .120 & .995 & & & \\
\hline HDL & -.011 & .025 & .188 & 1 & .665 & .989 & & & \\
\hline LDL & .006 & .007 & .909 & 1 & .340 & 1.006 & & & \\
\hline Constant & -44.958 & 17851.854 & .000 & 1 & .998 & .000 & & & \\
\hline \multicolumn{10}{|l|}{ Model 3.2} \\
\hline PTH & -.017 & .007 & 5.467 & 1 & .019 & .983 & \multirow{10}{*}{59.3} & \multirow{10}{*}{82.9} & \multirow{10}{*}{72.6} \\
\hline $\mathrm{CAD}(1)$ & .649 & .623 & 1.083 & 1 & .298 & 1.913 & & & \\
\hline $\mathrm{MI}(1)$ & 20.437 & 12784.724 & .000 & 1 & .999 & 751248842.438 & & & \\
\hline $\mathrm{AF}(1)$ & 21.428 & 13795.882 & .000 & 1 & .999 & 2023693999.998 & & & \\
\hline $\mathrm{HT}(1)$ & 1.468 & .470 & 9.770 & 1 & .002 & 4.341 & & & \\
\hline $\mathrm{DM}(1)$ & .294 & .529 & .309 & 1 & .579 & 1.342 & & & \\
\hline TRG & -.003 & .003 & .752 & 1 & .386 & .997 & & & \\
\hline HDL & .017 & .025 & .453 & 1 & .501 & 1.017 & & & \\
\hline LDL & .004 & .007 & .391 & 1 & .532 & 1.004 & & & \\
\hline Constant & -42.241 & 18808.915 & .000 & 1 & .998 & .000 & & & \\
\hline \multicolumn{10}{|l|}{ Model 3.3} \\
\hline D_VIT_OH_25 & .126 & .044 & 8.225 & 1 & .004 & 1.135 & \multirow{11}{*}{69.5} & \multirow{11}{*}{80.3} & \multirow{11}{*}{75.6} \\
\hline PTH & -.012 & .008 & 2.377 & 1 & .123 & .988 & & & \\
\hline $\mathrm{CAD}(1)$ & .467 & .659 & .503 & 1 & .478 & 1.595 & & & \\
\hline MI(1) & 20.884 & 12515.881 & .000 & 1 & .999 & 1174192607.473 & & & \\
\hline $\mathrm{AF}(1)$ & 21.839 & 13255.218 & .000 & 1 & .999 & 3050522065.125 & & & \\
\hline HT(1) & 1.403 & .501 & 7.848 & 1 & .005 & 4.067 & & & \\
\hline $\mathrm{DM}(1)$ & .155 & .561 & .077 & 1 & .782 & 1.168 & & & \\
\hline TRG & -.003 & .004 & .924 & 1 & .337 & .997 & & & \\
\hline HDL & .000 & .027 & .000 & 1 & .995 & 1.000 & & & \\
\hline LDL & .006 & .007 & .696 & 1 & .404 & 1.006 & & & \\
\hline Constant & -44.764 & 18230.411 & .000 & 1 & .998 & .000 & & & \\
\hline \multicolumn{10}{|c|}{$\begin{array}{l}\text { Model } 3.4 \text { applied to } 19 \\
\text { patients remained from } \\
\text { Model } 3.1\end{array}$} \\
\hline PTH & -.011 & .009 & 1.648 & 1 & .199 & .989 & \multirow{8}{*}{0.0} & \multirow{8}{*}{100.0} & \multirow{8}{*}{80.2} \\
\hline $\mathrm{CAD}(1)$ & .625 & .856 & .533 & 1 & .465 & 1.868 & & & \\
\hline $\mathrm{HT}(1)$ & .243 & .556 & .190 & 1 & .663 & 1.275 & & & \\
\hline $\mathrm{DM}(1)$ & -.640 & .762 & .704 & 1 & .401 & .527 & & & \\
\hline TRG & -.003 & .004 & .410 & 1 & .522 & .997 & & & \\
\hline HDL & -.006 & .030 & .038 & 1 & .846 & .994 & & & \\
\hline LDL & .001 & .008 & .006 & 1 & .937 & 1.001 & & & \\
\hline Constant & 2.574 & 1.971 & 1.706 & 1 & .192 & 13.117 & & & \\
\hline
\end{tabular}


factors [29]. The observation of a decreased incidence of CV disorders after the reduction of PTH levels by parathyroidectomy, renal transplantation, or calcimimetic agents supports the causal role of PTH in the development of $\mathrm{CV}$ disorders [29].

The third result of our study was that PTH, 25(OH)D, and HT were the most powerful markers for the prediction of stroke risk, even when all other cardiovascular risk factors were included in the analysis. When these three markers were compared with one another, $25(\mathrm{OH}) \mathrm{D}$ was the most powerful predictor, followed by HT and PTH in descending order. The weakest predictor was $\mathrm{CAD}$, which has no significant predicting ability in the presence of the above three markers. Schierbeck et al. found that both PTH and vitamin D were independently associated with both cardiovascular and allcause mortality [30]. These findings suggest that although both vitamin D and PTH appear to be separate risk factors for both stroke and all cardiovascular disorders combined, examining the two predictors in conjunction provides more accurate risk assessment for cardiovascular disorders. Our study limitation was the exclusion of an older patient group from the analysis to ensure equality in patient and control groups, which led to a relatively younger study population and, therefore, a potential bias.

In conclusion, PTH levels were increased, while $25(\mathrm{OH}) \mathrm{D}$ levels were decreased in patients with stroke. Both PTH and vitamin $\mathrm{D}$ appear to be separate risk factors for stroke. $25(\mathrm{OH}) \mathrm{D}$ was the most powerful marker for the predicting the stroke risk, followed by HT and PTH, in descending order. In addition to $25(\mathrm{OH}) \mathrm{D}, \mathrm{PTH}$ serum levels should be considered, and both predictors should be assessed in conjunction for more accurate determination of stroke risk. Additional studies are needed to investigate the effect of PTH on stroke risk, the interaction of both predictors, and possible conditions that may develop as a result of dysregulated vitamin $\mathrm{D}$ and PTH synthesis.

\section{Competing Interests}

The authors declare that there is no conflict of interests regarding the publication of this paper.

\section{References}

[1] G. S. Wannamethee, P. W. Welsh, O. P. Papacosta, L. Lennon, P. H. Whincup, and N. Sattar, "Elevated parathyroid hormone, but not vitamin $\mathrm{D}$ deficiency, is associated with increased risk of heart failure in older men with and without cardiovascular disease," Circulation: Heart Failure, vol. 7, no. 5, pp. 732-739, 2014.

[2] J. L. Anderson, R. C. Vanwoerkom, B. D. Horne et al., "Parathyroid hormone, vitamin $\mathrm{D}$, renal dysfunction, and cardiovascular disease: dependent or independent risk factors?" American Heart Journal, vol. 162, no. 2, pp. 331-339.e2, 2011.

[3] A. R. Folsom, A. Alonso, J. R. Misialek et al., "Parathyroid hormone concentration and risk of cardiovascular diseases: the Atherosclerosis Risk in Communities (ARIC) study," American Heart Journal, vol. 168, no. 3, pp. 296-302, 2014.
[4] P. Raggi, G. M. Chertow, P. U. Torres et al., "The ADVANCE study: a randomized study to evaluate the effects of cinacalcet plus low-dose vitamin D on vascular calcification in patients on hemodialysis," Nephrology Dialysis Transplantation, vol. 26, no. 4, pp. 1327-1339, 2011.

[5] J. C. Smith, M. D. Page, R. John et al., "Augmentation of central arterial pressure in mild primary hyperparathyroidism," Journal of Clinical Endocrinology and Metabolism, vol. 85, no. 10, pp. 3515-3519, 2000.

[6] G. Schillaci, G. Pucci, M. Pirro et al., "Large-artery stiffness: a reversible marker of cardiovascular risk in primary hyperparathyroidism," Atherosclerosis, vol. 218, no. 1, pp. 96-101, 2011.

[7] C. Goettsch, H. Iwata, and E. Aikawa, "Parathyroid hormone: critical bridge between bone metabolism and cardiovascular disease," Arteriosclerosis, Thrombosis, and Vascular Biology, vol. 34, no. 7, pp. 1333-1335, 2014.

[8] A. Lishmanov, S. Dorairajan, Y. Pak, K. Chaudhary, and A. Chockalingam, "Elevated serum parathyroid hormone is a cardiovascular risk factor in moderate chronic kidney disease," International Urology and Nephrology, vol. 44, no. 2, pp. 541-547, 2012.

[9] S. Pilz, A. Tomaschitz, C. Drechsler, A. Zittermann, J. M. Dekker, and W. März, "Vitamin D supplementation: a promising approach for the prevention and treatment of strokes," Current Drug Targets, vol. 12, no. 1, pp. 88-96, 2011.

[10] V. Majumdar, P. Prabhakar, G. B. Kulkarni, and R. Christopher, "Vitamin D status, hypertension and ischemic stroke: a clinical perspective," Journal of Human Hypertension, vol. 29, no. 11, pp. 669-674, 2015.

[11] D. M. Lee, D. Vanderschueren, S. Boonen et al., "Association of 25-hydroxyvitamin D, 1,25-dihydroxyvitamin D and parathyroid hormone with mortality among middle-aged and older European men," Age and Ageing, vol. 43, no. 4, pp. 528-535, 2014.

[12] P. Brøndum-Jacobsen, B. G. Nordestgaard, P. Schnohr, and M. Benn, "25-Hydroxyvitamin D and symptomatic ischemic stroke: an original study and meta-analysis," Annals of Neurology, vol. 73, no. 1, pp. 38-47, 2013.

[13] M. D. Witham, F. J. Dove, J. A. Sugden, A. S. Doney, and A. D. Struthers, "The effect of vitamin D replacement on markers of vascular health in stroke patients-a randomised controlled trial," Nutrition, Metabolism and Cardiovascular Diseases, vol. 22, no. 10, pp. 864-870, 2012.

[14] B. Daubail, A. Jacquin, J.-C. Guilland et al., "Serum 25-hydroxyvitamin D predicts severity and prognosis in stroke patients," European Journal of Neurology, vol. 20, no. 1, pp. 57-61, 2013.

[15] K.-Y. Park, P.-W. Chung, Y. B. Kim et al., "Serum vitamin D status as a predictor of prognosis in patients with acute ischemic stroke," Cerebrovascular Diseases, vol. 40, no. 1-2, pp. 73-80, 2015.

[16] C. Bosworth, M. C. Sachs, D. Duprez et al., "Parathyroid hormone and arterial dysfunction in the multi-ethnic study of atherosclerosis," Clinical Endocrinology, vol. 79, no. 3, pp. 429436, 2013.

[17] M. L. Melamed, J. A. Eustace, L. Plantinga et al., "Changes in serum calcium, phosphate, and PTH and the risk of death in incident dialysis patients: a longitudinal study," Kidney International, vol. 70, no. 2, pp. 351-357, 2006.

[18] G. A. Block, P. S. Klassen, J. M. Lazarus, N. Ofsthun, E. G. Lowrie, and G. M. Chertow, "Mineral metabolism, mortality, and morbidity in maintenance hemodialysis," Journal of the American Society of Nephrology, vol. 15, no. 8, pp. 2208-2218, 2004 . 
[19] H. Boström and A. Alveryd, "Stroke in hyperparathyroidism," Acta Medica Scandinavica, vol. 192, no. 4, pp. 299-308, 1972.

[20] Y. Sato, M. Kaji, N. Metoki, K. Satoh, and J. Iwamoto, "Does compensatory hyperparathyroidism predispose to ischemic stroke?” Neurology, vol. 60, no. 4, pp. 626-629, 2003.

[21] Q. Sun, A. Pan, F. B. Hu, J. E. Manson, and K. M. Rexrode, "25hydroxyvitamin D levels and the risk of stroke: a prospective study and meta-analysis," Stroke, vol. 43, no. 6, pp. 1470-1477, 2012.

[22] S. Pilz, H. Dobnig, J. E. Fischer et al., "Low vitamin D levels predict stroke in patients referred to coronary angiography," Stroke, vol. 39, no. 9, pp. 2611-2613, 2008.

[23] E. Giovannucci, Y. Liu, B. W. Hollis, and E. B. Rimm, "25Hydroxyvitamin D and risk of myocardial infarction in men: a prospective study," Archives of Internal Medicine, vol. 168, no. 11, pp. 1174-1180, 2008.

[24] E. Hagström, K. Michaëlsson, H. Melhus et al., "Plasmaparathyroid hormone is associated with subclinical and clinical atherosclerotic disease in 2 community-based cohorts," Arteriosclerosis, Thrombosis, and Vascular Biology, vol. 34, no. 7, pp. 1567-1573, 2014.

[25] R. Shroff, D. A. Long, and C. Shanahan, "Mechanistic insights into vascular calcification in CKD," Journal of the American Society of Nephrology, vol. 24, no. 2, pp. 179-189, 2013.

[26] G. Rashid, J. Bernheim, J. Green, and S. Benchetrit, "Parathyroid hormone stimulates endothelial expression of atherosclerotic parameters through protein kinase pathways," American Journal of Physiology-Renal Physiology, vol. 292, no. 4, pp. F1215-F1218, 2007.

[27] N. Bansal, L. Zelnick, C. Robinson-Cohen et al., "Serum parathyroid hormone and 25-hydroxyvitamin D concentrations and risk of incident heart failure: the Multi-Ethnic Study of Atherosclerosis," Journal of the American Heart Association, vol. 3, no. 6, Article ID e001278, 2014.

[28] M. D. Walker, J. Fleischer, T. Rundek et al., "Carotid vascular abnormalities in primary hyperparathyroidism," Journal of Clinical Endocrinology and Metabolism, vol. 94, no. 10, pp. 38493856, 2009.

[29] E. Hagström, P. Hellman, T. E. Larsson et al., "Plasma parathyroid hormone and the risk of cardiovascular mortality in the community," Circulation, vol. 119, no. 21, pp. 2765-2771, 2009.

[30] L. L. Schierbeck, T. S. Jensen, U. Bang, G. Jensen, L. Køber, and J.-E. B. Jensen, "Parathyroid hormone and vitamin Dmarkers for cardiovascular and all cause mortality in heart failure," European Journal of Heart Failure, vol. 13, no. 6, pp. 626632, 2011. 


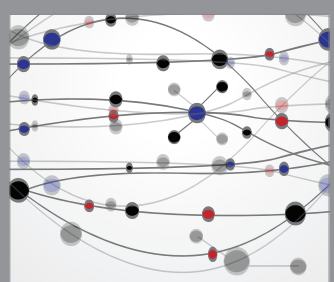

The Scientific World Journal
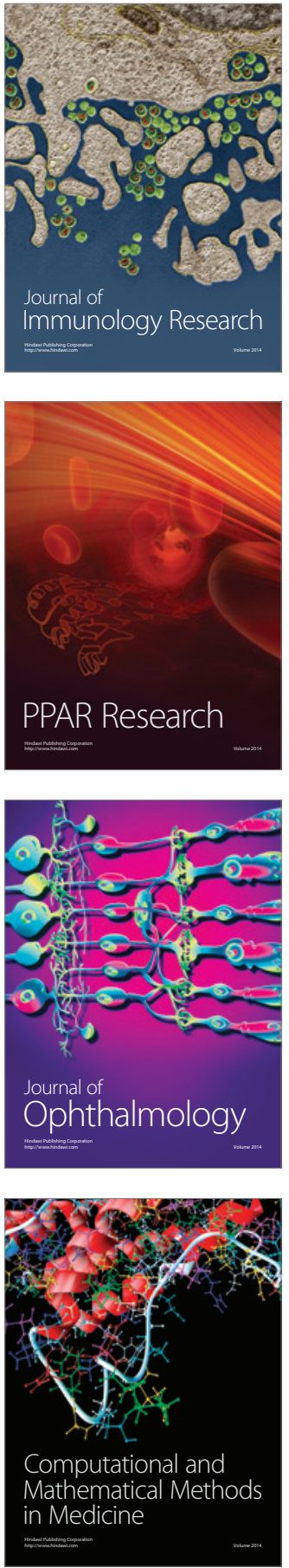

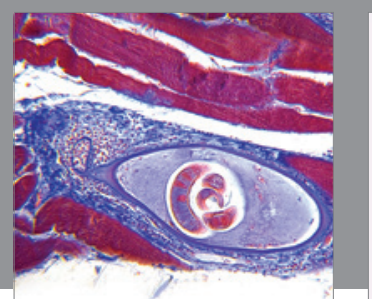

Gastroenterology Research and Practice
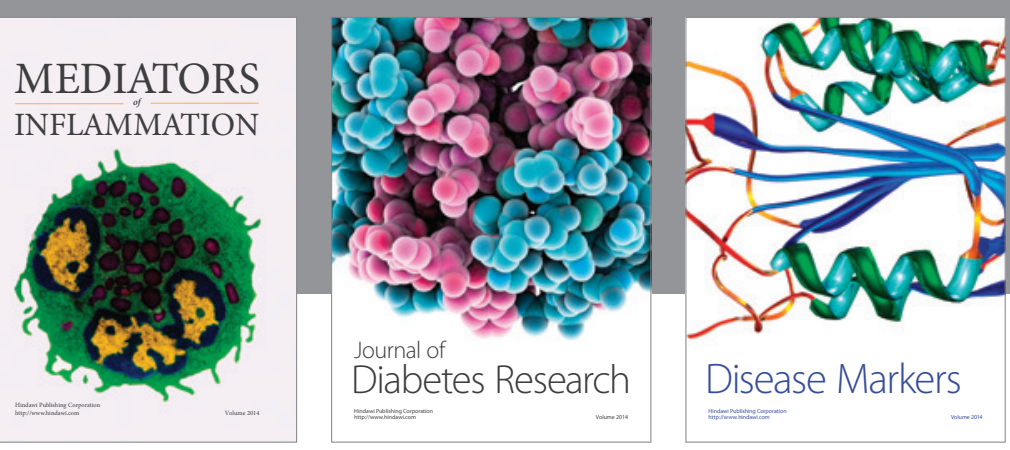

Disease Markers

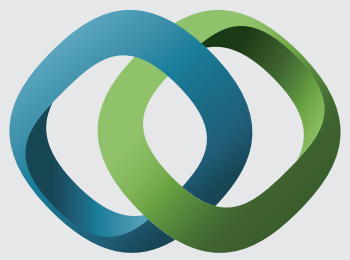

\section{Hindawi}

Submit your manuscripts at

https://www.hindawi.com
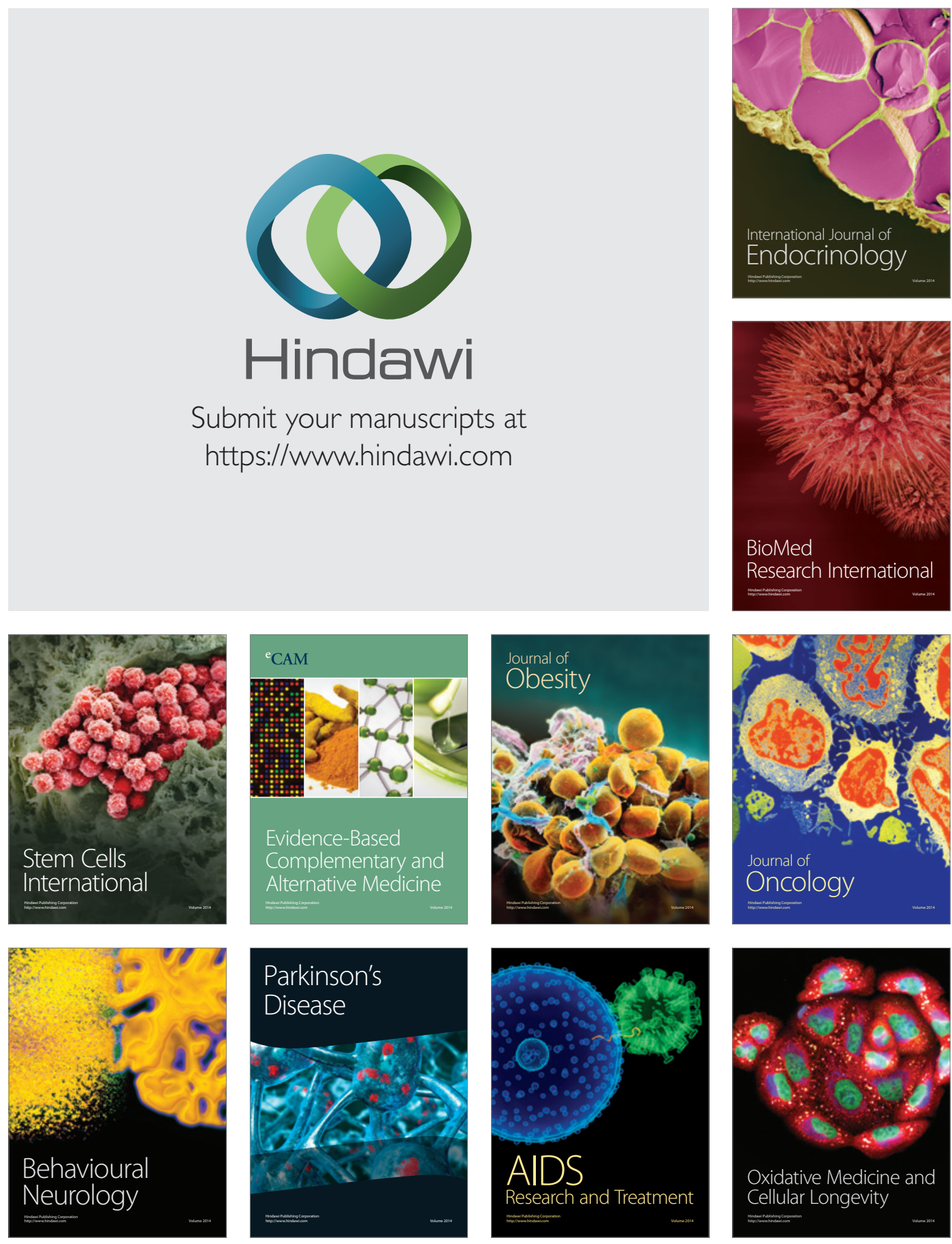